\title{
Inserção profissional e formação continuada de egressos de cursos de graduação em Educação Física
}

\author{
CDD. 20.ed. 371.12 \\ 796.017 \\ http://dx.doi.org/10.1590/1807-55092015000300475
}

\author{
William das Neves SALLES* \\ Gelcemar Oliveira FARIAS* \\ J uarez Vieira do NASCIMENTO* \\ *Centro de Desportos, \\ Universidade Federal \\ de Santa Catarina. \\ **Centro de Ciências \\ daSaúde edo Esporte, \\ Universidade do Esta- \\ do de Santa Catarina.
}

\section{Resumo}

0 objetivo do estudo foi analisar aspectos da inserção profissional e perspectivas de formação continuada de egressos dos cursos de bacharelado e licenciatura em Educação Física da Universidade Federal de Santa Catarina. Os participantes foram 63 egressos (34 bacharéis e 29 licenciados) concluintes entre o segundo semestre de 2009 e o segundo semestre de 2010, os quais responderam às questões de um questionário online, especialmente construído e validado para a pesquisa, que procurou obter informações referentes à sua inserção profissional e às perspectivas de formação continuada. De maneira geral, observou-se que a maioria dos formados atuava na área profissional de interesse, predominantemente em instituições privadas. A falta de experiência de atuação e a baixa remuneração oferecida pelos locais de trabalho foram consideradas as principais barreiras da inserção profissional. Em contrapartida, foram percebidos como facilitadores deste processo a amplitude de opções de intervenção destinadas ao profissional de Educação Física, bem como os conhecimentos adquiridos durante o curso realizado. A remuneração mensal da maior parte dos egressos empregados foi de até três salários mínimos. Verificou-se o interesse dos egressos de ambos os cursos pela realização de atividades de formação continuada em Educação Física, com destaque comum para cursos de especialização e/ou de mestrado nas áreas de atividade física direcionada à promoção da saúde. As evidências encontradas podem fornecer indicadores acerca da efetividade das reformulações curriculares realizadas nos cursos de graduação em Educação Física da UFSC, bem como contribuir para o aprimoramento contínuo da formação inicial oferecida aos estudantes.

Palavras-chave: Profissão; Mercado de trabalho; Estudantes; Universidade; Educação física.

\section{Introdução}

A atual conjuntura global, caracterizada por rápidos avanços tecnológicos, tem implicado em mudanças nas diversas áreas da vida humana ${ }^{1}$, dentre as quais destaca-se o mercado de trabalho e, consequentemente, a formação profissional. A "revolução da informação", com efeito, tem gerado impactos de incerteza e instabilidade no mercado de trabalho, visto que o surgimento de novas oportunidades e de modalidades de atuação contrasta com o desemprego crescente em determinados campos de intervenção. Esta dinamicidade do mercado implica, naturalmente, no surgimento de novos contextos de atuação e na necessidade de profissionais adaptados às respectivas exigências ${ }^{2}$.

No caso específico da Educação Física, a literatura consultada ${ }^{3}$ identifica cinco grandes áreas de atuação profissional: a) escola: educação infantil, ensino fundamental, ensino médio e ensino superior; b) saúde: hospitais, clínicas de recuperação cardíaca e fisioterápica, clínicas de reeducação motora e centros de tratamento de distúrbios motores e mentais; c) lazer: clubes, hotéis, estâncias hidrominerais, hotéis-fazenda, SESC, SESI e animação de festas e eventos; d) esporte, nos níveis amador e profissional: clubes esportivos, empresas, prefeituras e clubes sociais; e) empresa: indústrias, academias e escolinhas de modalidades esportivas em geral. Para outros autores $^{1,4-5}$, a diversificação percebida nas áreas de atuação do profissional reflete, basicamente, dois grandes campos de intervençáo: o âmbito escolar (sistema de ensino público e privado) e as demais áreas externas 
ao respectivo contexto, dentre as mais conhecidas a atividade física relacionada à promoção da saúde, o lazer, o esporte e as atividades de gestão empresarial.

As mudanças ocorridas no mercado de trabalho da Educação Física, nos anos recentes, podem ser sintetizadas pela gradativa redução de postos de trabalho nas escolas e clubes (campos mais tradicionais), contrastando com o aumento progressivo de oportunidades em locais como empresas, hospitais, prefeituras e indústrias (campos não tradicionais) ${ }^{2}$. Certamente, o aumento na valorização da prática de atividades físicas como promotoras de bem-estar e qualidade de vida $^{6}$, além da preocupação com a manutenção da saúde e com a existência de um modelo de corpo a ser alcançado ${ }^{7}$, comprovam que os campos de atuação do profissional de Educação Física têm se ampliado para as mais diversas áreas, não mais se restringindo ao ambiente escolar e aos clubes esportivos ${ }^{2}$.

Como perspectiva futura para a atuação na área, destaca-se o convívio frequente da Educação Física com riscos e desafios provocados pela velocidade crescente de mudanças na sociedade contemporânea ${ }^{8}$. Sob esta perspectiva, revela-se a necessidade da busca incessante pelo aprimoramento das competências de intervenção profissional, de modo a melhorar a qualidade dos serviços prestados e, com isso, garantir o espaço de mercado pretendido ${ }^{8}$. De fato, a tendência de aumento na competitividade implica, necessariamente, no desenvolvimento de atitudes dos profissionais para aprimorar constantemente sua competência para a intervenção ${ }^{8}$.

Um aspecto a destacar é o aumento gradativo da oferta e da procura por concursos públicos específicos para profissionais de Educação Física fora da tradicional função de professor da área da educação, com destaque para os âmbitos da saúde, da promoção social, da segurança e do esporte 9 . Assim, tornam-se essenciais os processos de formação continuada e de participação ativa do profissional de Educação Física nas discussóes e deliberaçóes sobre as principais questôes críticas relacionadas com sua intervençáo profissional, no intuito de promover o desenvolvimento da profissão e o atendimento qualificado às mutáveis expectativas sociais?

Com a preocupaçáo de compreender determinados aspectos da inserção profissional de egressos de cursos de graduação, investigaçôes têm sido desenvolvidas, tanto na área da Educaçáo Física ${ }^{10-13}$, como na docên$\mathrm{Cia}^{14-15} \mathrm{e}$ em outros contextos ${ }^{16-18}$. Dentre as temáticas abordadas, destacam-se as condiçóes de trabalho desses profissionais ${ }^{19}$, os locais de sua intervençáo ${ }^{20}$, a remuneração por eles recebida ${ }^{4,21}$ e a qualidade de vida na percepçâo do trabalhador docente ${ }^{22}$. Considerando a importância da formaçáo continuada para o sucesso profissional no mercado de trabalho altamente competitivo dos tempos atuais, estudos também têm manifestado preocupaçáo em investigar, nos egressos, suas perspectivas de realização de cursos de pós-graduação "lato" e "stricto sensu", além de conhecer as áreas de interesse de especialização destes sujeitos ${ }^{10,18,23}$.

Apesar de se terem sido encontrados, na literatura consultada, alguns estudos que abordam o egresso dos cursos de formação inicial no mercado de trabalho ${ }^{10-11}$, são escassas as pesquisas que procuraram investigar a inserçáo profissional e as perspectivas de formação continuada de egressos formados sob as novas diretrizes curriculares para os cursos de licenciatura ${ }^{24-25}$ e de bacharelado ${ }^{26}$ em Educação Física. Buscando suprir esta lacuna, o presente estudo se propôs analisar aspectos da inserção profissional e perspectivas de formação continuada de egressos dos cursos de bacharelado e licenciatura em Educação Física da Universidade Federal de Santa Catarina (UFSC).

\section{Método}

O estudo se caracteriza como transversal, do tipo descritivo-diagnóstico e de levantamento de informaçōes. Quanto à abordagem do problema, caracteriza-se como uma pesquisa quali-quantitativa ${ }^{27}$.

A população investigada foi constituída pelas três primeiras turmas de egressos formados a partir da nova proposta curricular para a formaçáo inicial em Educaçáo Física da UFSC, implementada no ano de 2006, com número de matrícula cadastrado a partir do primeiro semestre do ano de 2006 e formaçáo concluída entre o segundo semestre de 2009 e o segundo semestre de 2010, o que totalizou 63 indivíduos elegíveis (34 bacharéis e 29 licenciados). Todos os formados enquadrados nos critérios supracitados consentiram em participar da pesquisa, resultando em amostra composta por $100 \%$ dos indivíduos da populaçãoalvo. A escolha dos participantes foi intencional (amostragem não probabilística), considerando-se os objetivos da investigação. Foram excluídos da amostra todos os egressos com número de matrícula anterior ao primeiro semestre de 2006 (mesmo que os referidos sujeitos tenham cursado disciplinas oferecidas pelo 
currículo novo), bem como os egressos formados após o segundo semestre de 2010.

$\mathrm{Na}$ coleta de dados foi utilizado um questionário online especificamente construído e validado para o presente estudo. Tal questionário foi elaborado com auxílio de uma ferramenta para a criação de formulários "online" do Google Docs. O instrumento, composto por 16 questões (abertas, fechadas ou de múltipla escolha), buscou reunir informaçóes identificadoras dos sujeitos da pesquisa, investigar determinados aspectos relacionados à inserção profissional e, por fim, conhecer seus interesses em realizar alguma atividade de formação continuada em Educação Física, bem como a(s) modalidade(s) pretendida(s) de especialização. A validação de conteúdo e a avaliação de clareza de linguagem do questionário foram realizadas por 13 especialistas da área. $\mathrm{O}$ resultado final do processo indicou coeficientes de 0,96 para a validade de conteúdo e 0,93 para a clareza de linguagem das questóes do instrumento, o que foi considerado adequado para torná-lo aplicável ${ }^{28}$.
Após a aprovação do projeto de pesquisa pelo Comitê de Ética em Pesquisa com Seres Humanos da UFSC (parecer no 2002/2011), os egressos foram contatados por meio de seus endereços eletrônicos ("e-mails"), cadastrados junto à coordenadoria dos cursos de Educação Física da referida instituição, e receberam todas as informaçóes sobre a procedência e os objetivos da pesquisa, na forma de um Termo de Consentimento Livre e Esclarecido. Um novo "e-mail" foi enviado aos sujeitos que aceitaram participar do estudo, no qual constava o "link" da página eletrônica na qual o questionário encontrava-se hospedado.

No processo de análise dos dados, as informaçóes quantitativas coletadas foram inseridas no "software" SPSS Statistics 17.0. Posteriormente, utilizaram-se os recursos da estatística descritiva (frequência simples e percentual) e inferencial (teste Exato de Fisher). O nível de significância adotado para os resultados foi de 5\%. As informaçôes qualitativas, por sua vez, foram inseridas e analisadas no "software" Nvivo 9.2, mediante emprego de recursos técnicos da análise de conteúdo ${ }^{29}$.

\section{Resultados}

O grupo de 63 egressos, predominantemente do gênero feminino, possuía idade média de 25,63 \pm 3,91 anos no momento da coleta de dados (TABELA 1). De maneira geral, a maioria dos egressos (cerca de 78\%) encontrava-se solteira, o que também é percebido ao se considerar separadamente os cursos de bacharelado $(73,5 \%)$ e de licenciatura (83\%). Observou-se predominância de moradia local dos egressos, visto que $86 \%$ destes indivíduos residiam na região da grande Florianópolis (São José, Palhoça e Florianópolis). Apenas 14\% dos egressos moravam em outras regióes, Estados ou países.

TABELA 1 - Caracterização dos egressos participantes do estudo.

\begin{tabular}{llccc}
\hline Variáveis & \multicolumn{1}{c}{ Indicadores } & Geral n (\%) & Bacharelado n (\%) & Licenciatura n (\%) \\
\hline \multirow{2}{*}{ Sexo } & Masculino & $26(41,3)$ & $14(41,2)$ & $12(41,4)$ \\
& Feminino & $37(58,7)$ & $20(58,8)$ & $17(58,6)$ \\
\multirow{2}{*}{ Estado civil } & Solteiro(a) & $49(77,8)$ & $25(73,5)$ & $24(82,8)$ \\
& Casado(a) & $13(20,6)$ & $9(26,5)$ & $4(13,8)$ \\
& Outro & $1(1,6)$ & $0(0,0)$ & $1(3,4)$ \\
Local de & Grande Florianópolis & $54(86,0)$ & $28(82,4)$ & $26(89,7)$ \\
residência & Outras regiôes/Brasil & $8(13,0)$ & $5(14,7)$ & $3(10,3)$ \\
& Outros países & $1(1,6)$ & $1(2,9)$ & $0(0,0)$ \\
Ano/semestre & $2006 / 1$ & $27(42,9)$ & $19(55,9)$ & $8(27,6)$ \\
de ingresso & $2006 / 2$ & $16(25,4)$ & $6(17,6)$ & $10(34,5)$ \\
no curso & $2007 / 1$ & $20(31,7)$ & $9(26,5)$ & $11(37,9)$ \\
& $2009 / 2$ & $8(12,7)$ & $8(24,0)$ & $0(0,0)$ \\
Ano/semestre & $2010 / 1$ & $24(38,1)$ & $10(29,0)$ & $14(48,0)$ \\
de conclusáo & $2010 / 2$ & $31(49,2)$ & $16(47,0)$ & $15(52,0)$ \\
do curso & & $63(100,0)$ & $34(54,0)$ & $29(46,0)$ \\
\hline Total & &
\end{tabular}


A maior porcentagem dos egressos ingressou no curso de Educação Física no primeiro semestre de 2006. Apenas $13 \%$ do total dos egressos concluiu o curso de formação inicial no semestre 2009/2, sendo todos do bacharelado. Nos semestres subsequentes (2010/1; 2010/2), houve aumento gradativo e progressivo no percentual de indivíduos que conseguiu concluir os cursos, tanto no bacharelado (29\%; $47 \%$, respectivamente) quanto na licenciatura (48\%; $52 \%)$.

A maior parte dos egressos do curso de bacharelado (43\%) tinha interesse em exercer, logo após a conclusão da formação inicial, alguma ocupação direcionada à área de atividade física relacionada à promoção da saúde (QUADRO 1). Parcelas menores desejavam atuar nas áreas de avaliação e prescrição de exercícios (29\%) e gestáo e treinamento esportivo (21\%). Apenas pequena parte dos sujeitos investigados (7\%) manifestou interesse por atuar em alguma atividade profissional não relacionada aos três eixos temáticos norteadores do curso realizado.

Quando são analisados os dados referentes às preferências profissionais de atuação dos egressos do curso de licenciatura, um fato chama muito a atenção: a maior parte $(42 \%)$ dos indivíduos desejava atuar em áreas externas ao contexto escolar. Apenas $41 \%$ dos egressos apresentou interesse em exercer a profissão no sistema de ensino formal tradicional (Educação Básica). Os demais sujeitos (17\%) revelaram preferência por trabalhar com modalidades diferenciadas de ensino da Educação Física, tais como a Educação Física adaptada e a Educação Física direcionada a populações indígenas.

QUADRO 1-Áreas de atuação de interesse dos egressos, no momento da conclusão do curso.

\begin{tabular}{|l|l|}
\hline \multicolumn{1}{|c|}{ Bacharelado } & \multicolumn{1}{c|}{ Licenciatura } \\
\hline - Atividade Física e Saúde & $\bullet$ Fora da escola \\
- Avaliação e Prescrição de Exercícios & $\bullet$ Ensino Fundamental \\
- Gestão e Treinamento Esportivo & $\bullet$ Modalidades de Ensino \\
- Outras & $\bullet$ Educação Infantil \\
& $\bullet$ Ensino Médio \\
\hline
\end{tabular}

No que diz respeito à situaçáo profissional dos egressos, constatou-se que a maioria deles $(\mathrm{B}=$ $91 \% ; \mathrm{L}=83 \%$ ) encontrava-se inserida no mercado de trabalho, no momento da coleta de dados. Dos indivíduos empregados, a maior parte deles $(\mathrm{B}=$ $81 \% ; \mathrm{L}=71 \%$ ) exercia funções profissionais de seu interesse na área de Educação Física. Contudo, $10 \%$ dos egressos pesquisados $(\mathrm{L}=12 \% ; \mathrm{B}=6 \%)$ não trabalhavam com atividades relacionadas à Educação Física.

O QUADRO 2 destaca as principais barreiras percebidas pelos egressos no momento da inserção no mercado de trabalho. Foram mencionados como principais fatores dificultantes a falta de experiência na área de interesse e a baixa remuneração oferecida pelos empregadores. Os bacharéis também elencaram problemas referentes à ocupação excessiva de postos de trabalho por estagiários ou por profissionais sem a devida habilitação; à falta de conhecimentos específicos para desenvolver adequadamente suas ocupaçóes profissionais; à saturação do mercado de trabalho. Os licenciados, por sua vez, reconheceram, como barreiras adicionais: a desvalorização sofrida pela profissão na sociedade; as deficiências curriculares na formaçáo inicial realizada; a escassez de concursos para contratação de professores efetivos.

QUADRO 2 - Principais barreiras percebidas pelos egressos no momento da inserção profissional.

\begin{tabular}{|l|l|}
\hline \multicolumn{1}{|c|}{ Bacharelado } & \multicolumn{1}{c|}{ Licenciatura } \\
\hline - Baixa remuneração & $\bullet$ Falta de experiência \\
- Falta de experiência & $\bullet$ Baixa remuneração \\
- Excesso de estagiários e/ou profissionais sem habilitação na área & $\bullet$ Desvalorização da profissão \\
- Falta de conhecimentos específicos & $\bullet$ Deficiências curriculares \\
- Saturação do mercado de trabalho & $\bullet$ Falta de concursos para professores efetivos \\
\hline
\end{tabular}


Os principais elementos percebidos como facilitadores da entrada no mercado de trabalho estão dispostos no QUADRO 3. Tanto os bacharéis como os licenciados destacaram que as experiências e os conhecimentos obtidos no curso de formação inicial compreendem os principais fatores contribuintes para a inserção profissional bem-sucedida. A amplitude de opções para a atuaçáo profissional também foi reconhecida como um importante auxiliar neste processo.

QUADRO 3 - Principais facilitadores percebidos pelos egressos no momento da inserção profissional.

\begin{tabular}{|c|c|}
\hline Bacharelado & Licenciatura \\
\hline $\begin{array}{l}\text { - Experiências e conhecimentos adquiridos durante o } \\
\text { curso de graduaçáo } \\
\text { - Realização de estágios durante a graduação } \\
\text { - Amplitude do mercado de trabalho } \\
\text { - Sem facilitadores } \\
\text { - Bom conceito da UFSC }\end{array}$ & $\begin{array}{l}\text { - Experiências e conhecimentos adquiridos durante o } \\
\text { curso de graduação } \\
\text { - Amplitude do mercado de trabalho } \\
\text { - Bom conceito da UFSC } \\
\text { - Valorização crescente da profissão } \\
\text { - Sem facilitadores }\end{array}$ \\
\hline
\end{tabular}

A visibilidade e o bom prestígio da UFSC perante o meio acadêmico e a comunidade circunvizinha foram apontados pelos investigados como elementos auxiliares para a inserção profissional. Por fim, pequena parcela dos egressos de ambos os cursos não apontaram facilitadores para o ingresso no mercado de trabalho. Para estes indivíduos, a dedicação pessoal, a persistência e a habilidade de comunicação constituem os elementos-chave para se conseguir sucesso na transição da universidade para o ambiente laboral propriamente dito.
A TABELA 2 apresenta informaçóes referentes à inserção profissional dos egressos investigados, com destaque para a atuação (ou não) na área de interesse, a renda bruta mensal derivada do posto de trabalho na área de Educação Física e o tipo de instituição ou organização em que os egressos desempenhavam suas atribuições profissionais. É importante destacar que não foram considerados, nas análises realizadas, os egressos que mencionaram não atuar em alguma atividade relacionada à área de abrangência da Educação Física.

TABELA 2 - Relação entre o curso realizado pelos egressos e a atuação na área de interesse, a renda mensal e a categoria da instituição de trabalho.

\begin{tabular}{lcccc}
\hline & \multicolumn{3}{c}{ Curso } & \\
\cline { 2 - 4 } Variáveis & $\begin{array}{c}\text { Geral } \\
\mathbf{n}(\%)\end{array}$ & $\begin{array}{c}\text { Bacharelado } \\
\mathbf{n}(\%)\end{array}$ & $\begin{array}{c}\text { Licenciatura } \\
\mathbf{n}(\%)\end{array}$ & p-valor $^{\mathbf{1}}$ \\
\hline Atuaçáo na área de interesse & & & & \\
Sim & $42(84,0)$ & $25(86,2)$ & $17(81,0)$ & 0,706 \\
Não & $8(16,0)$ & $4(13,8)$ & $4(19,0)$ & 1,000 \\
Renda mensal & & & & \\
Até 3 salários mínimos & $35(70,0)$ & $20(68,9)$ & $6(28,6)$ & \\
Mais de 3 salários mínimos & $15(30,0)$ & $9(31,1)$ & $2(9,5)$ & 0,274 \\
Tipo de instituiçáo de trabalho & & & $13(61,9)$ & \\
Pública & $3(6,0)$ & $1(3,4)$ & $6(28,6)$ & \\
Privada & $37(74,0)$ & $24(82,8)$ & $21(42,0)$ & \\
Outras & $10(20,0)$ & $4(13,8)$ & $29(58,0)$ & \\
\hline Total & $50(100,0)$ & & & \\
\hline
\end{tabular}

A maior parte dos investigados $(\mathrm{B}=86 \% ; \mathrm{L}=81 \%)$ exercia funçóes profissionais de seu interesse na área de Educação Física. Observou-se o predomínio da esfera privada $(B=83 \% ; \mathrm{L}=62 \%)$ sobre as demais organizaçôes. Quando se considera a renda bruta mensal dos egressos, percebeu-se que a maioria deles ( $\mathrm{B}=69 \%$; $\mathrm{L}$ $=71 \%$ ) tinha rendimentos mensais de até três salários mínimos, sendo que apenas 31\% dos bacharéis e 29\% dos licenciados apresentava renda mensal acima desta faixa. Como os egressos de ambos os cursos revelaram 
semelhança no perfil profissional, não foi encontrada diferença estatisticamente significativa entre os grupos.

Diagnosticou-se o interesse da maioria dos egressos $(\mathrm{B}=79 \% ; \mathrm{L}=83 \%)$ em realizar alguma atividade de formação continuada em Educação Física, especialmente sob a forma de cursos de pós-graduação "lato sensu" (especialização) e/ou "stricto sensu" (mestrado e doutorado). Em relação às áreas de interesse de pós-graduação (QUADRO 4 ), verificou-se que os bacharéis tinham, como foco principal, a especialização em fisiologia do exercício, ao passo que a maioria dos licenciados pretendia realizar (ou já realizava) atividades de formação continuada relacionadas à prática pedagógica.

QUADRO 4 - Principais áreas de interesse de formação continuada mencionadas pelos egressos.

\begin{tabular}{|l|l|}
\hline \multicolumn{1}{|c|}{ Bacharelado } & \multicolumn{1}{c|}{ Licenciatura } \\
\hline - Fisiologia do exercício & $\bullet$ Teoria e prática pedagógica \\
- Atividade física e saúde & $\bullet$ Atividade física e saúde \\
$\bullet$ Treinamento esportivo & $\bullet$ Fisiologia do exercício \\
\hline
\end{tabular}

O interesse em se especializar na área de atividade física e saúde foi marcante tanto no grupo de bacharéis $(22,2 \%)$ como no de licenciados $(26,1 \%)$. Alguns bacharéis ainda destacaram que pretendiam realizar cursos direcionados à área de treinamento esportivo, enquanto que parte dos licenciados identificaram na fisiologia do exercício sua área de interesse para a continuidade dos estudos.

\section{Discussão}

A principal limitação do presente estudo se manifesta na falta de sensibilidade do instrumento de pesquisa utilizado em identificar as atividades e experiências vivenciadas pelos egressos no decorrer do curso de formação inicial realizado, as quais podem ter contribuído para desenvolver competências pessoais e profissionais que, por sua vez, facilitaram seu ingresso no mercado de trabalho e em suas opçóes de formação continuada.

O maior contingente de egressos do sexo feminino reflete o que a literatura denomina de feminização do ensino superior. A análise da evolução da distribuiçẫo da população brasileira com nível universitário nos últimos 30 anos do século $\mathrm{XX}^{30}$ revelou melhora progressiva nos índices de escolaridade das mulheres. Se, por um lado, em 1970, apenas $25 \%$ dos graduandos das IES brasileiras eram mulheres, no ano 2000 o contingente passou a ser majoritariamente feminino (53\%).

A maior proporção de bacharéis interessados em desenvolver atividades profissionais na área de atividade física e saúde, logo após a conclusão do curso de formação inicial, encontra correspondência em obras da literatura consultada. Alguns pesquisadores ${ }^{31}$ reconhecem que a adoção de estilos de vida ativos e saudáveis (com prática regular de atividades e exercícios físicos) vem sendo valorizada pela sociedade e pelas organizaçôes internacionais de saúde, especialmente pela comprovação científica de seus benefícios biológicos (melhoria da aptidão física, redução do risco de ocorrência ou mortalidade por doenças cardiovasculares...), psicológicos (aumento da percepçấo de bem-estar, redução da ansiedade, do estresse e da depressão...) e sociais (inserção em um grupo de prática, ampliação dos vínculos sociais, conquista de novas amizades...).

A ampliação das possibilidades de atuação do profissional de Educação Física para ambientes não tradicionais ${ }^{1,4,20}$, tais como hospitais, equipes multiprofissionais (por exemplo, os Núcleos de Atenção à Saúde da Família - NASF), clínicas de reabilitação, grupos de terceira idade, ou mesmo a consolidação da intervenção em contextos habituais (como as academias de ginástica e musculação e os clubes esportivos) são motivadas não só pela dinâmica do mercado e da sociedade ${ }^{8}$, mas também pelo próprio caráter bidimensional da formação inicial, seja pelo viés da educação, seja pelo da saúde ${ }^{32}$. Desta maneira, a grande procura social e o reconhecimento da importância dos serviços oferecidos pelo profissional de Educação Física nestes contextos, aliadas às características do currículo da formaçáo acadêmica oferecida pela instituição investigada (o qual apresenta um eixo temático de aprofundamento relacionado à Atividade Física e Saúde), parecem contribuir para justificar o maior interesse atribuído 
pelos bacharéis do presente estudo em exercer suas atividades profissionais na área de atividade física relacionada à promoçáo da saúde.

Cabe destacar que a maioria dos licenciados manifestou preferência pela atuação em ambientes externos à escola. Uma possível justificativa para o achado é a própria amplitude de possibilidades de intervençáo nestes locais. Em um estudo ${ }^{19}$ realizado com 82 egressos do curso de licenciatura em Educação Física da Universidade Federal de São Carlos (UFSCar), formados no período entre 1997 e 2003, encontrou-se que apenas 13 sujeitos (16\% do total) estavam, efetivamente, exercendo sua profissão em ambientes escolares. Os 69 indivíduos (84\%) restantes trabalhavam em áreas externas ao contexto escolar, com destaques para as academias de ginástica (25,5\%), Serviço Social do Comércio - SESC (16\%) e clubes esportivos (11\%). Ao ser estudada a inserção mercadológica de 306 egressos dos cursos de Educação Física de IES do Estado do Rio de Janeiro ${ }^{10}$, encontrou-se percentual muito baixo de indivíduos desenvolvia atividades na escola $(16,01 \%)$, ao passo que $42,81 \%$ atuavam na área não formal. Contudo, deve ser feita a ressalva de que os egressos de ambos os estudos se formaram em cursos que adotavam o modelo curricular frequentemente denominado de "licenciatura ampliada", ou seja, estes achados são anteriores à vigência das novas diretrizes para a organização curricular, que contribuíram para a separação da formação inicial em licenciatura ${ }^{24-25}$ e bacharelado ${ }^{26}$.

O baixo interesse em atuar na escola também pode ser explicado pela precariedade da estrutura que boa parte das instituiçôes formais de ensino oferece aos professores de Educaçáo Física, bem como pela falta de valorização desse profissional nestes ambientes. Um estudo ${ }^{12}$ realizado com 35 professores de Educação Física do Ensino Fundamental da rede pública de ensino de Santa Maria/RS diagnosticou insatisfaçáo dos docentes com as condiçôes de trabalho, principalmente no que se refere à falta de espaço físico e de materiais adequados para a prática da Educação Física. Os docentes também manifestaram insatisfação com o salário recebido e preocupação com o desprestígio e com a desvalorização da disciplina junto à própria escola e à sociedade, o que reduzia seus níveis motivacionais para o trabalho ${ }^{12}$. Ao examinar as crenças docentes de 20 professores de Educação Física das escolas públicas de Educaçáo Básica em Porto Alegre/RS, outra investigação ${ }^{33}$ verificou que a baixa remuneração paga ao professorado é o principal argumento para a crença no baixo reconhecimento social e econômico da profissão perante a sociedade.
A insuficiência de adequadas condiçôes espaciais e materiais para as aulas de Educação Física também interferiu decisivamente para solidificar, no pensamento desses professores, a crença no baixo valor docente de suas atividades ${ }^{33}$.

O perfil de inserção profissional com predominância de egressos empregados, no presente estudo, é semelhante ao encontrado em pesquisa ${ }^{19}$ que procurou analisar a formação e a atuação profissional de 82 egressos do curso de licenciatura em Educação Física da UFSCar, no período compreendido entre 1997 e 2003. No referido estudo, apenas 15 indivíduos (18\%) não trabalhavam na área ou não estavam trabalhando ao responderem o instrumento de pesquisa, enquanto 67 (82\%) estavam atuando em áreas específicas da Educação Física. Em investigação ${ }^{11}$ realizada com 65 egressos do curso de licenciatura em Educação Física do Centro Universitário Feevale, concluintes no período entre 1976 e 2000, constatou-se que grande parte da amostra envolvida (80\%) não revelou grandes dificuldades para encontrar posto de trabalho na área logo após a conclusão do curso de graduação em Educação Física, o que corrobora os achados do presente estudo.

As grandes barreiras identificadas pelos egressos para a inserção profissional estáo relacionadas à falta de experiência e à baixa remuneração oferecida pelos postos de trabalho e apresentam semelhanças às encontradas em outras investigaçóes realizadas com diversos cursos de graduação. Ao entrevistarem 20 jovens (nove graduandos e 11 recém-graduados) pertencentes a vários cursos (Arquitetura, Ciências da Computação Fisioterapia, Medicina, Direito e Psicologia) de determinada IES brasileira, investigadores ${ }^{17}$ constataram que o fator percebido como maior empecilho à inserção profissional bem-sucedida é a falta de experiência, com $16,6 \%$ dos apontamentos. Com temática investigativa semelhante, pesquisadores ${ }^{34}$ procuraram diagnosticar a situação do jovem, com idade entre 15 e 24 anos, no mercado de trabalho brasileiro, buscando avaliar a magnitude e os determinantes do desemprego da juventude brasileira utilizando dados da Pesquisa Nacional por Amostra de Domicílios (PNAD) de 1998. Os resultados mostraram que a experiência contribui para aumentar a probabilidade de o jovem encontrar-se empregado. Nesta perspectiva, as análises estatísticas realizadas demonstraram que o aumento de um ano de experiência faz crescer, em média, $20 \%$ a probabilidade de que o jovem consiga emprego ${ }^{34}$.

A baixa remuneração, por sua vez, é identificada por alguns estudos como sendo importante fator desmotivante e gerador de insatisfação no trabalho do 
profissional de Educação Física ${ }^{35-36}$. Uma investigação ${ }^{22}$, realizada com 654 docentes de Educação Física da rede pública estadual de ensino do Paraná, demonstrou que a dimensão "remuneração e compensação" foi responsável pela maioria dos casos de insatisfaçáo do trabalho. Nessa perspectiva, um estudo ${ }^{13}$ que buscou compreender aspectos da atuação profissional e das condiçôes de trabalho de 53 profissionais formados em Educação Física atuantes em academias de ginástica de Brasília/DF verificou insatisfaçáo geral percebida pelos participantes com a remuneração recebida: $45 \%$ dos indivíduos perceberam sua remuneração como totalmente incompatível a pouco compatível, $25 \%$ afirmaram ser razoavelmente compatível e apenas $30 \%$ diagnosticaram como compatível ou totalmente compatível, levando-se em conta fatores como o nível de capacitação percebido, a qualidade dos serviços prestados, a realidade do mercado de trabalho em academias e a carga horária de trabalho ${ }^{13}$.

No que diz respeito aos elementos facilitadores da inserção profissional percebidos pelos egressos do presente estudo, a experiência anterior na área de atuação desejada, bem como a diversidade e a ampliação das opçóes de atuação em Educação Física, são elementos reconhecidamente importantes que auxiliam o egresso em seu processo de inserção profissional ${ }^{1,8}$. Em estudo ${ }^{17}$ realizado com estudantes e egressos de diversos cursos de graduação, por exemplo, foi constatado em $80 \%$ das respostas dos indivíduos que os fatores percebidos como facilitadores da inserção profissional estavam relacionados à conquista de experiências e conhecimentos anteriores, os quais contribuiriam para o aumento da sensação de controle e de segurança na atuação profissional.

A maior parte dos egressos investigados atuava na área de seu interesse no momento da coleta de dados, sobretudo em instituiçóes privadas e com renda bruta de até três salários mínimos. Com o intuito de conhecer a inserção profissional de 137 nutricionistas egressos do Centro Universitário do Leste de Minas Gerais (Unileste-MG), investigadores $^{37}$ diagnosticaram que $79 \%$ dos indivíduos desenvolviam suas atividades profissionais na área de Nutrição, ao passo que $21 \%$ atuavam em outras esferas profissionais. Ao estudarem a situação profissional de 89 graduados no curso de Nutrição da Faculdade de Saúde Pública (USP), no período de 1990 a 1996, pesquisadores ${ }^{16}$ observaram que, do total de nutricionistas, $79,8 \%$ trabalhavam na área de Nutrição, $14,6 \%$ não estavam trabalhando no período do levantamento de dados e 5,6\% informaram estar trabalhando fora da área. Tais achados, portanto, são equivalentes aos do presente estudo, respeitando-se as especificidades dos cursos e dos campos de atuação profissional em ambos os casos.

O perfil de renda mensal dos egressos do presente estudo está em conformidade com os dados apresentados por estudo ${ }^{4}$ cujo objetivo foi mapear o mercado de trabalho do profissional de Educação Física brasileiro. No referido trabalho, encontrou-se que, entre os profissionais de Educação Física com emprego formalizado, a média salarial nacional foi de $\mathrm{R} \$ 1.124,18$, ou seja, dentro da faixa correspondente a três salários mínimos atuais. No entanto, é importante ressaltar que os dados obtidos ${ }^{4}$ eram provenientes de um levantamento realizado pela Relação Anual de Informaçôes Sociais (RAIS) do Ministério do Trabalho e Emprego (MTE), no ano de 2006. Àquela época, o salário mínimo vigente em território nacional era de $\mathrm{R} \$ 350,00$, o que, de certa forma, valorizava mais os rendimentos mensais encontrados, em comparação com os achados da presente investigação. Pesquisa ${ }^{21}$ que analisou a valorização profissional e social na percepção de 15 professores de Educaçáo Física Escolar, docentes da rede pública estadual e municipal da cidade de Bocaiúva/MG, identificou que a maioria dos sujeitos $(76 \%)$ recebia de um a quatro salários mínimos, sendo apenas $24 \%$ os que apresentavam rendimentos mensais superiores a esta faixa. Tais achados são, também, semelhantes aos do presente estudo.

A maior proporção de egressos com atuação na esfera privada, em comparação com a esfera pública, pode ser justificada pela própria caracterização do mercado de trabalho na área. Com efeito, a maior parte dos postos de trabalho destinados ao profissional de Educação Física é privada, tais como os clubes esportivos, academias de ginástica, clínicas de reabilitação, hotéis e grupos de terceira idade (estes últimos que, além de tudo, têm ofertado crescente número de vagas nos últimos anos) $)^{1,8}$.

Embora o salário médio do setor público supere o do setor privado ${ }^{38}$, a inserção profissional nestes ambientes, de maneira geral, é mais difícil em comparação com a esfera privada, pois o perfil de qualificação da mão-de-obra na esfera pública é melhor do que no setor privado ${ }^{38}$. Levando-se em consideraçáo que os egressos do presente estudo eram recém-graduados, no momento da coleta de dados, é plausível que ainda náo tivessem tido o tempo necessário para complementar adequadamente sua formação profissional e, consequentemente, pleitear cargos públicos em igualdade de condiçôes com indivíduos mais experientes. Além disso, a entrada no setor público é concretizada, em grande parte das vezes, mediante a aprovação em 
concursos públicos (estes, de periodicidade variável). Com base nestas explicações, é possível, ao menos, elencar alguns fatores que auxiliem a justificar os achados do presente estudo.

A considerável parcela de egressos interessados na realização de atividades de formação continuada, de certa forma, já era esperada. A formação continuada, que tem por objetivos possibilitar a continuidade do processo de formação inicial e atender às necessidades constantes que o graduado encontra em obter subsídios para seu desenvolvimento intelectual e profissio$\mathrm{nal}^{11}$, permite contínuo aprimoramento e atualização de conhecimentos, habilidades e atitudes inerentes ao exercício laboral. Os cursos de especialização "lato sensu”, por exemplo, podem despertar o interesse dos egressos por serem oportunidades de atenuar o distanciamento entre a formação inicial e o contexto de intervenção, bem como de melhorar a qualificação para o "lócus" da intervenção. As atividades de pósgraduação têm sido consideradas como aceleradores do desenvolvimento da área, sendo capazes de gerar impactos significativos não só para a formação profissional, mas também para a própria sociedade ${ }^{23}$.

Raros são os estudos vinculados aos bacharéis que revelam como ocorre sua participação em programas de formação continuada. Por outro lado, com os profissionais da licenciatura, esta ação já foi investigada por alguns autores ${ }^{39-40}$, resultando em melhor compreensão acerca deste processo no âmbito escolar. As fases que os docentes costumam percorrer desde sua aderência em programas de formação continuada até seu total engajamento costumam ser divididas em: pré-capacitação; resistência; tomada de consciência; engajamento; aprofundamento; transformação ${ }^{40}$. A fase inicial da carreira (pré-capacitação), foco de abordagem deste estudo, costuma ser caracterizada ou pelo otimismo disfarçado, ou pelo pessimismo exagerado ${ }^{40}$.

Esta grande procura por cursos de formação continuada em Educação Física pode estar relacionada, também, ao aumento progressivo da oferta de vagas pelos cursos de graduação, o que implica no crescimento do número de indivíduos formados e inseridos no mercado de trabalho ${ }^{23}$. Diante desta realidade, o egresso é constantemente estimulado a buscar o aperfeiçoamento de conhecimentos técnicos e práticos, no intuito de conquistar diferenciais para sua intervenção profissional ${ }^{18}$.

$\mathrm{O}$ interesse destacado dos egressos dos cursos de Educação Física da UFSC em complementar sua formação inicial revela semelhanças com os resultados obtidos junto a estudantes formados no curso de
Educação Física da UFSCar ${ }^{19}$. Nesta investigação, constatou-se que $64,6 \%$ dos egressos optaram pelo prosseguimento formal dos estudos, por meio da realização de cursos de especialização e de mestrado. Em outra pesquisa ${ }^{18}$, desenvolvida com egressos de um curso de Nutrição, observou-se que 66\% dos formados buscaram alguma modalidade de pós-graduação, sendo as mais frequentes a especialização em Nutrição e o mestrado - o que também revela similaridades com a situação encontrada no presente estudo. Entretanto, os resultados da presente investigaçáo diferem da realidade apresentada em universidades do Rio de Janeiro ${ }^{10}$, em que apenas 30,4\% dos egressos indicaram realizar algum tipo de curso de formação continuada.

Este estudo permitiu conhecer a situação profissional dos egressos dos cursos de bacharelado e de licenciatura em Educação Física da UFSC, além de possibilitar a identificação de suas perspectivas de formação continuada nas áreas de interesse. De maneira geral, observou-se que a maioria dos formados estava atuando na área profissional de interesse, predominantemente em instituiçóes privadas. A falta de experiência de atuação e a baixa remuneração oferecida pelos locais de trabalho foram consideradas as principais barreiras da inserção profissional. Em contrapartida, foram percebidos como facilitadores deste processo a amplitude de opçóes de intervenção destinadas ao profissional de Educação Física, bem como os conhecimentos adquiridos durante o curso realizado. A remuneração mensal da maior parte dos egressos empregados foi de até três salários mínimos.

Verificou-se o interesse dos egressos de ambos os cursos pela realização de atividades de formação continuada em Educação Física, com destaque comum para cursos de especialização e/ou mestrado nas áreas de atividade física direcionada à promoção da saúde. Os bacharéis, predominantemente, mencionaram a intenção de aprimorar seus conhecimentos na área de fisiologia do exercício, enquanto os licenciados perspectivaram especializar-se em programas de aprimoramento relacionados prática pedagógica.

As evidências encontradas podem fornecer indicadores acerca da efetividade das reformulaçóes curriculares realizadas nos cursos de graduação em Educação Física da UFSC, além de contribuir para o aprimoramento contínuo da formação inicial oferecida a seus estudantes. Como sugestão para futuras investigaçóes, seria interessante que as mesmas procurassem compreender como ocorre o processo de transição acadêmico-profissional dos egressos dos cursos de Educação Física organizados sob as novas diretrizes nacionais, analisando com profundidade 
sua relaçáo com as experiências vivenciadas pelos estudantes ao longo da formação inicial. Desta maneira, haveria a possibilidade de se diagnosticar os fatores que influenciam este processo, com base nos quais poderiam ser organizadas estratégias institucionais que melhorassem a qualidade da formaçáo oferecida, bem como minimizassem possíveis falhas curriculares e estruturais que pudessem contribuir para a falta de envolvimento dos estudantes com o curso.
Além disso, poderiam ser explorados delineamentos longitudinais que permitissem compreender com maior aprofundamento o período de tempo compreendido entre a formatura dos egressos e a conquista do primeiro emprego na área ou o engajamento em atividades de formação continuada, o que poderia sinalizar determinadas barreiras ou facilitadores desse processo de transição entre a universidade e o mercado de trabalho.

\begin{abstract}
Employability and continued education of graduates from graduation courses on Physical Education

The aim of the study was to analyze aspects of employability and prospects for continued education of graduates from the bachelor and degree courses on Physical Education from Federal University of Santa Catarina. The participants were 63 graduates (34 bachelors and 29 licensees) graduated between the second semester of 2009 and the second semester of 2010, who answered the questions from an online questionnaire especially constructed and validated for the study, which sought information regarding their employability and prospects of continued education. In general, it was observed that most of the graduates was working in the professional area of interest, mainly in private institutions. The lack of working experience and the low payment offered by the workplaces were considered the main barriers to employability. On the other hand, were perceived as facilitators of this process the range of intervention options available to the professional of Physical Education, as well as the knowledge acquired during the initial education. The monthly remuneration of the most employed graduates was up to three minimum wages. It was the interest of graduates from both courses performing activities of continued education on Physical Education, with common highlight to specialization and / or master's courses on the areas of physical activity related to health promotion. The found evidence may provide indicators of the effectiveness of curricular changes made in undergraduate courses on Physical Education from UFSC, as well as contribute to the continuous improvement of the initial education offered to the students.
\end{abstract}

KeY WORDS: Occupation; Labor market; Students; University; Physical Education.

\title{
Referências
}

1. Antunes AC. Mercado de trabalho e educação física: aspectos da preparação profissional. Rev Educ. 2007;10:141-9.

2. Feitosa WMN, Nascimento JV. As competências específicas do profissional de educação física que atua na orientação de atividades físicas: um estudo Delphi. Rev Bras Ci Mov. 2003;11:19-26.

3. Oliveira AAB. A formação profissional em educação física: legislação, limites e possibilidades. In: Souza Neto S, Hunger D, organizadores. Formação profissional em educação física: estudos e pesquisas. Rio Claro: Biblioética; 2006. p.17-32.

4. Proni MW. Universidade, profissão educaçâo física e o mercado de trabalho. Motriz. 2010;16:788-98.

5. Ilha FRS. O curso de licenciatura em educação física e os desafios da formação profissional: o processo de ensinar e aprender a docência [dissertação]. Santa Maria (RS): Universidade Federal de Santa Maria; 2010.

6. Nahas MV. Atividade física, saúde e qualidade de vida: conceitos e sugestôes para um estilo de vida ativo. Londrina: Midiograf; 2010.

7. Ramos GNS. A formação profissional em educação física e as novas diretrizes: reestruturação curricular. In: Souza Neto S, Hunger D, organizadores. Formação profissional em educação física: estudos e pesquisas. Rio Claro: Biblioética; 2006. p.147-58. 
8. Nascimento JV. Formação profissional em educação física: contextos de desenvolvimento curricular. Montes Claros: Unimontes; 2002.

9. Galindo AG. Mercado de trabalho da educação física: um breve ensaio sobre os impactos da regulamentação profissional. Ciclo de palestras da Semana do Profissional de Educação Física; 2005; Macapá, BR. 2005. Macapá: Secretaria Estadual de Desporto e Lazer; 2005. p.21-39.

10. Steinhilber J. Inserção mercadológica dos egressos das Instituiçôes de Ensino Superior de Educação Física do Estado do Rio de Janeiro [dissertação]. Rio de Janeiro (RJ): Universidade Castelo Branco; 1999.

11. Piccoli JCJ, Menezes FCL. O perfil do egresso do curso de educação física do Centro Universitário Feevale. Lect Educ Fís Deportes. 2006;98:1. Disponível em: http://www.efdeportes.com/efd98/feevale.htm.

12. Krug HN. Vale a pena ser professor... de educação física escolar? Lect Educ Fís Deportes. 2008;122:1. Disponível em: http://www.efdeportes.com/efd122/vale-a-pena-ser-professor-de-educacao-fisica-escolar.htm.

13. Mendes AD. Atuação profissional e condiçôes de trabalho do educador físico em academias de atividades físicas [dissertação]. Brasília (DF): Universidade de Brasília; 2010.

14 Mariano ALS. O início da docência e o espetáculo da vida na escola: abrem-se as cortinas. In: Lima EF, organizador. Sobrevivências: no início da docência. Brasilia: Lïber Livro; 2006. p.17-26.

15 Corsi AM. Dificuldades de professoras iniciantes e condiçóes de trabalho nas escolar. In: Lima EF, organizador. Sobrevivências: no início da docência. Brasilia: Lïber Livro; 2006. p.53-65.

16. Gambardella AMD, Ferreira CF, Frutuoso MFP. Situação profissional de egressos de um curso de nutrição. Rev Nutr. 2000;13:37-40

17. Melo SL, Borges LO. A transição da universidade ao mercado de trabalho na ótica do jovem. Psicol Ciênc Prof. 2007; 27:376-95.

18. Santana VIT, Pereira LMR. Atuação profissional dos egressos de um curso de nutrição. Rev Interdiscip Novafapi. 2010;3:24-8.

19. Ramos G, Gonçalves JL, Paschoalino LC, Santos L. Egressos do curso de educação física da Universidade Federal de São Carlos (1997-2003): formação e atuação. Mov Percepc. 2008;9:249-65.

20. Souza SC, Loch MR. Intervenção dos profissionais de educação física nos núcleos de apoio à saúde da família em municípios do Norte do Paraná. Rev Bras Ativ Fís Saúde. 2011;16:5-10.

21. Veloso JM, Mourão MGM, Maciel RC, Gomes MCS, Soares WD. O professor de educaçáo física: uma análise da valorização profissional e social. Lect Educ Fís Deportes. 2010;144:1. Disponível em: http://www.efdeportes.com/ efd144/o-professor-de-educacao-fisica-valorizacao-social.htm.

22. Moreira HR, Nascimento JV, Sonoo CN, Both J. Qualidade de vida do trabalhador docente em educação física do Estado do Paraná, Brasil. Rev Bras Cineantropom Desempenho Hum. 2010;12:435-42.

23. Kokubun E. Pós-graduação em educação física. Rev Bras Educ Fís Esporte. 2006;20:31-3.

24. Brasil. Conselho Nacional de Educação. Resolução CNE/CP n. 1, de 18 de fevereiro de 2002. Institui as Diretrizes Curriculares Nacionais para a Formação de Professores da Educação Básica, em nível superior, curso de licenciatura, de graduação plena. Diário Oficial da União, Brasília (4 mar. 2002).

25. Brasil. Conselho Nacional de Educação. Resoluçâo CNE/CP n. 2, de 19 de fevereiro de 2002. Institui a duração e a carga horária dos cursos de licenciatura, de Graduação Plena, de Formação de Professores da Educação Básica em nível superior. Diário Oficial da União, Brasília (4 mar. 2002).

26. Brasil. Conselho Nacional de Educação. Resoluçáo CNE/CP n. 7, de 31 de março de 2004. Institui as Diretrizes Curriculares Nacionais para os cursos de graduação em Educação Física, em nível superior de graduação plena. Diário Oficial da União, Brasília (5 abr. 2004).

27. Gil AC. Como elaborar projetos de pesquisa. 5a ed. São Paulo: Atlas; 2010.

28. Dal Pupo J, Schütz GR, Santos SG. Instrumentos de medida. In: Santos SG, organizadora. Métodos e técnicas de pesquisa quantitativa aplicada à educação física. Florianópolis: Tribo da Ilha; 2011. p.141-90.

29. Richardson R J. Pesquisa social: métodos e técnicas. São Paulo: Atlas; 1989.

30. Guedes MC. O contingente feminino de nível universitário nos últimos trinta anos do século XX: Reversão de um quadro desigual. 14º Encontro Nacional de Estudo Populacional da ABEP; 2004; Caxambu, BR. Caxambu: ABEP; 2004. p.1-17.

31. Howley ET, Franks BD. Manual de condicionamento físico. 5a ed. Porto Alegre: Artmed; 2008.

32. Quint FO, Matiello Júnior E, Martinez JFN, Bacheladenski, MS. Reflexóes sobre a inserção da educação física no Programa Saúde da Família. Motrivivência. 2005;24:81-95. 
33. Molina Neto V. Crenças do professorado de educação física das escolas públicas de Porto Alegre/RS, Brasil. Movimento. 2003;9:145-69.

34. Silva NDV, Kassouf AL. A exclusão social dos jovens no mercado de trabalho brasileiro. Rev Bras Estud Popul. 2002; 19:99-115.

35. Folle A, Lemos CAF, Nascimento JV, Both J, Farias GO. Carreira no magistério público e nível de qualidade de vida no trabalho docente em Educação Física. Motriz. 2008;14:210-21.

36. Farias GO, Lemos CAF, Both J, Nascimento JV, Folle A. Carreira docente em educação física: uma abordagem sobre a qualidade de vida no trabalho de professores da rede estadual de ensino do Rio Grande do Sul. Rev Educ Fís/UEM. 2008;19:11-22.

37. Letro LCMAO, Jorge MN. Inserção profissional dos nutricionistas egressos do Centro Universitário do Leste de Minas Gerais: Unileste, MG. Nutr Gerais. 2010;4:668-80.

38. IPEA. Instituto de Pesquisa Econômica Aplicada. Salários no setor público versus salários no setor privado no Brasil. Brasília: IPEA; 2009 [citado 21 jul. 2013]. Disponível em: http://www.ipea.gov.br/sites/000/2/ comunicado_presidencia/09_12_10_ComunicaPresi_37_Salarios_S.publico.pdf.

39. Rodrigues L. Da prática à teoria: uma experiência em educação básica [tese]. Barcelona (ESP): Universidad Autônoma de Barcelona, Faculdad de Ciências de la Educación; 1987.

40. Gonçalves LR, Passos SRMMD. Processo de desenvolvimento profissional do professor: educaçáo continuada. Paradoxa. 2004;10:45-56.

\section{Agradecimentos}

Aos integrantes do Núcleo de Pesquisa em Pedagogia do Esporte da Universidade Federal de Santa Catarina, pelo apoio na análise de dados e pelo auxílio na escrita do estudo.

\begin{tabular}{r|l} 
ENDEREÇO & \\
William das Neves Salles & \\
Douglas Seabra Levier, 376 & Recebido para publicação: 22/ 09/2013 \\
orianópolis - SC - BRASIL & Revisado: 29/12/2014 \\
williamdnsalles@gmail.com & Aceito: 05/01/2015 \\
&
\end{tabular}

